\title{
The multi-objective genetic algorithm optimization, of a superplastic forming process, using ansys
}

\author{
Gavril Grebenişan ${ }^{1, *}$, Nazzal Salem ${ }^{2}$ \\ ${ }^{1}$ University of Oradea, e-mail: grebe@uoradea.ro, Romania \\ ${ }^{2}$ ZAQRA University, nsalem@zu.edu.jo, Jordan
}

\begin{abstract}
In the industrial practice, the product is intended to be flawless, with no technological difficulty in making the profile shapes. If this product results without defects, then any Finite Elements Method (FEM) based simulation can support that technology. A technology engineer does not propose, very often to analyze the simulation of the design technology, but rather to try to optimize a solution that he feels feasible. Experiments used as the basis for numerical optimization analysis support their research in the field of superplastic forming. Determining the influence of input parameters on the output parameters, Determining the optimal shape of the product and the optimal initial geometry, the prediction of the cracks and possibly the fractures, the prediction of the final thickness of the sheet, these are the objectives of the research and optimization for this project. The results of the numerical simulations have been compared with the measurements made on parts and sections of the parts obtained by superplastic forming. Of course, the consistency of the results, costs, benefits, and times required to perform numerical simulations are evaluated, but they are not objectives for optimizing the superplastic forming process.
\end{abstract}

\section{Introduction}

The engineering design system is an extremely laborious and delicate interdisciplinary process that requires cooperation between designers in various engineering fields. This means the technological design is considered to be a complex process and needs to be approached very carefully. Design engineering requires hypotheses that need to be adopted for the further development of models that can undergo analysis, verification, and experiments. The project starts, always with the analysis of several variants. For most applications, the entire design project can be subdivided into different subproblems that can then be independently addressed. Each subproblem can thus be presented as a design optimum to be mathematically solved, M. Diehl, F. Glineur, E. Jarlebring, W. Michiels [1].

For technology engineers to apply optimization methods to a project, they need to have a detailed understanding of both theory and algorithms and their specific techniques. This is due, first of all, to the fact that considerable effort is needed to apply optimization techniques to practical problems to achieve an improvement in the performance of the studied product. For this reason, perhaps, optimization has been used, in particular, to help the projection process, namely to support decision-making, not to develop concepts, or to develop a detailed project.

Generally, for technology engineers, optimization issues are reduced to minimization a function (a cost function, for example), or maximizing a function (a "profit" function), a function that is subject to constraints (mathematically, these may be some inequalities or equations), the optimization problem being called the nonlinear programming problem. Its general form is, A. D. Belegundu and T. R. Chandrupatla [2]:

Minimize:

$$
\mathbf{f}(\mathbf{x}, \mathbf{y})
$$

subject to:

$$
\begin{aligned}
& g_{i}(x, y) \leq 0 \quad i=1, \ldots, m \\
& h_{j}(x, y) \geq 0, \quad j=1 \ldots \ell
\end{aligned}
$$

\footnotetext{
*Corresponding author: grebe@uoradea.ro
} 
where

$$
\begin{gathered}
\mathbf{x} \in \mathbb{R}^{\mathbf{n}_{\mathbf{c}}}, \mathbf{y} \in \mathbb{R}^{\mathbf{n}_{\mathbf{i}}} \\
\mathbf{x}_{\mathbf{l}} \leq \mathbf{x} \leq \mathbf{x}_{\mathbf{u}} \\
\mathbf{y}_{\mathbf{l}} \leq \mathbf{y} \leq \mathbf{y}_{\mathbf{u}}
\end{gathered}
$$

Not often (it can be said that this is the real challenge for an engineer regarding a genuinely delicate optimization problem), both a minimization and a maximization may be required, of course, on various criteria, clearly set, the problem is extremely complex and cost-generating. For example, a structural engineer may like to minimize the mass of the product, but would also like to increase mechanical rigidity. At this point, several goals can be discussed simultaneously. Mathematically, the problem with multiple targets (or "attributes") may be stated as, A. D. Belegundu and T. R. Chandrupatla [2]:

$$
\operatorname{minimize} \mathbf{f}=\left[\mathbf{f}_{\mathbf{1}}(\mathbf{x}), \mathbf{f}_{\mathbf{2}}(\mathbf{x}), \ldots, \mathbf{f}_{\mathbf{m}}(\mathbf{x})\right]
$$

subject to $\boldsymbol{x} \in \boldsymbol{\Omega}$

When, very rarely, it happens that only one optimum criterion $\mathbf{x}_{\mathbf{o p t}}$ minimizes all the objectives, the problem is solved instantly. Most of the time, however, the optimization criteria are in conflict. In this situation, the optimization problem is solved by weighting the criteria:

$$
\begin{gathered}
\text { minimize } \mathbf{f}=\boldsymbol{\omega}_{\mathbf{1}} \mathbf{f}_{\mathbf{1}}(\mathbf{x})+\boldsymbol{\omega}_{\mathbf{2}} \mathbf{f}_{\mathbf{2}}(\mathbf{x})+\cdots \\
\text { subject to } \boldsymbol{x} \in \mathbf{\Omega}
\end{gathered}
$$

where the weights $\boldsymbol{\omega}_{i}$ are positives, and $\sum \boldsymbol{\omega}_{i}=\mathbf{1}$. Choosing the sizes of these weights is based on experimental data.

Another approach, quite common, is to designate one of the criteria as a priority, and to constrain the values for the weights of the other criteria:

$$
\begin{gathered}
\text { minimize } \mathbf{f}_{\mathbf{1}}(\mathbf{x}) \\
\text { subject to } \mathbf{f}_{\mathbf{2}}(\mathbf{x}) \leq \boldsymbol{c}_{2} \\
\cdots \\
\mathbf{f}_{\mathbf{m}}(\mathbf{x}) \leq \boldsymbol{c}_{\boldsymbol{m}} \\
\boldsymbol{x} \in \mathbf{\Omega}
\end{gathered}
$$

Even if the use of a set of values for weights, $\boldsymbol{\omega}_{i}$, or limits, $\boldsymbol{c}_{\boldsymbol{i}}$, generates an optimum, $\mathbf{x}_{\mathbf{o p t}}$, that coresponds to all criteria, an engineer must be able to answer the question, what if the diferent selection of set of values will done, the results are different? Then comes the answer: we must take into account the sensitivities of the output parameters with respect to the input parameters, and the Parameters Correlation, the computation and optimization module, provided by ANSYS as a feature, mathematics and graphics at the same time.

\section{Optimization procedure}

The studied part, shown in Fig. 1, is hemispherical with flange, G. Grebenişan and S. Mureşan [3]. The blank is fixed, with friction, between the two components of the forming die, on its perimeter and the entire assembly is heated in a horizontal oven, for superplastic forming at high temperature (under the half of melting temperature of the material, i.e. approximately $460\left[{ }^{\circ} \mathrm{C}\right]$, for Supral 100, commercial named, this Aluminium alloy. The gas pressure will act and deform the sample, with a very low strain rate $\dot{\varepsilon}=2.5 \times 10^{-3}\left[s^{-1}\right]$. The material is modeled with an Anand Viscoplasticity law as described by M.M. Rahman [4]. The strain distribution on the workpiece section and resultant thickness of the specimen it's possible to be very variable from one area to another, leading to a nonhomogeneous thickness distribution in the final component. This will also induce higher stress zones.The authors J.-P. Ponthot, J.-P. Kleinermann [5] proposed an approach to avoid these problems. The mentioned authors proposed to use the following procedure: to determine the initial piece geometry that would lead, at the end of forming process, to the prescribed uniform distribution of the thickness of the final workpiece transversal section. Furthermore, we chosen as input parameters the sample diameter and the thickness of the sample.

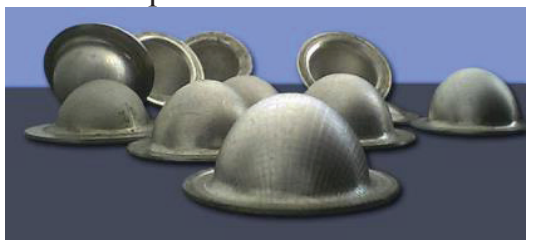

a)-hemispherical parts

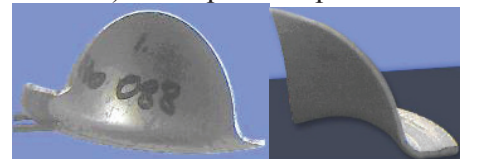

b)-hemispherical (midsection and quarter section)

Fig. 1. Studied parts

Later, in this workpaper, a Design of Experiments(DOE) is presented and is easy to found that the study involves a sampling point which not always conducive to lowering the time needed for the analysis.

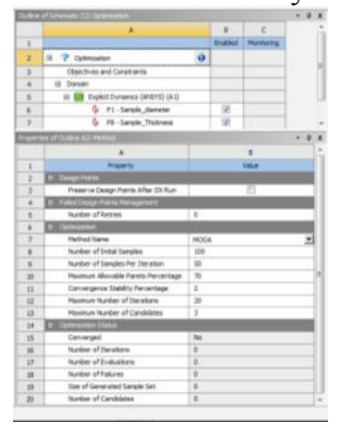

Fig. 2. The Settings of Direct Optimization

\footnotetext{
* Corresponding author: grebe@uoradea.ro
} 
Table 1. Raw optimization data

\begin{tabular}{|c|c|c|c|c|c|}
\hline $\begin{array}{l}\text { Nam } \\
\text { e }\end{array}$ & $\begin{array}{l}\text { P1 - } \\
\text { Sampl } \\
\text { e_dia } \\
\text { meter } \\
(\mathrm{mm})\end{array}$ & $\begin{array}{l}\text { P8 - } \\
\text { Sampl } \\
\text { e_Thic } \\
\text { kness } \\
(\mathrm{mm})\end{array}$ & $\begin{array}{l}\text { P5 - } \\
\text { Equivale } \\
\text { nt Stress } \\
\text { Maximu } \\
\text { m (MPa) }\end{array}$ & $\begin{array}{l}\text { P6 - } \\
\text { Total } \\
\text { Deforma } \\
\text { tion } \\
\text { Maximu } \\
\text { m (mm) }\end{array}$ & $\begin{array}{l}\text { P7 - } \\
\text { Equivale } \\
\text { nt } \\
\text { Plastic } \\
\text { Strain } \\
\text { Maximu } \\
\text { m (mm } \\
\text { mm^-1) }^{\wedge}\end{array}$ \\
\hline 1 & 18.02 & 1.08 & 488.91 & 15.08 & 0.24 \\
\hline 2 & 18.06 & 1.20 & 495.75 & 15.31 & 0.22 \\
\hline 3 & 18.10 & 1.14 & 484.52 & 15.22 & 0.22 \\
\hline 4 & 18.14 & 1.26 & 485.42 & 15.44 & 0.24 \\
\hline 5 & 18.18 & 1.11 & 494.11 & 15.20 & 0.22 \\
\hline 6 & 18.22 & 1.23 & 535.34 & 15.38 & 0.22 \\
\hline 7 & 18.26 & 1.17 & 499.01 & 15.30 & 0.22 \\
\hline 8 & 18.30 & 1.29 & 517.91 & 15.15 & 0.23 \\
\hline 9 & 18.34 & 1.10 & 491.14 & 15.25 & 0.22 \\
\hline 10 & 18.38 & 1.22 & 554.64 & 15.19 & 0.23 \\
\hline 11 & 18.42 & 1.16 & 466.27 & 15.15 & 0.23 \\
\hline 12 & 18.46 & 1.28 & 476.75 & 15.13 & 0.25 \\
\hline 13 & 18.50 & 1.13 & 533.48 & 15.34 & 0.24 \\
\hline 14 & 18.54 & 1.25 & 505.48 & 15.24 & 0.24 \\
\hline 15 & 18.58 & 1.19 & 520.15 & 15.14 & 0.24 \\
\hline 16 & 18.62 & 1.31 & 433.10 & 15.16 & 0.25 \\
\hline 17 & 18.66 & 1.09 & 513.64 & 15.35 & 0.25 \\
\hline 18 & 18.70 & 1.21 & 484.48 & 15.06 & 0.24 \\
\hline 19 & 18.74 & 1.15 & 466.67 & 15.09 & 0.25 \\
\hline 20 & 18.78 & 1.27 & 492.00 & 15.10 & 0.73 \\
\hline 21 & 18.82 & 1.12 & 470.99 & 15.13 & 0.27 \\
\hline 22 & 18.86 & 1.24 & 522.50 & 15.04 & 0.26 \\
\hline 23 & 18.90 & 1.18 & 538.05 & 15.19 & 0.25 \\
\hline 24 & 18.94 & 1.30 & 723.67 & 15.09 & 0.73 \\
\hline 25 & 18.98 & 1.10 & 468.50 & 15.10 & 0.27 \\
\hline 26 & 19.02 & 1.22 & 612.17 & 15.11 & 0.26 \\
\hline 27 & 19.06 & 1.16 & 441.66 & 15.08 & 0.26 \\
\hline 28 & 19.10 & 1.28 & 667.51 & 15.04 & 0.73 \\
\hline 29 & 19.14 & 1.13 & 604.14 & 15.25 & 0.27 \\
\hline 30 & 19.18 & 1.25 & 462.46 & 15.14 & 0.27 \\
\hline 31 & 19.22 & 1.19 & 560.77 & 15.24 & 0.27 \\
\hline 32 & 19.26 & 1.31 & 654.86 & 15.33 & 0.65 \\
\hline$\cdots$ & $\cdots$ & $\cdots$ & $\cdots$ & $\cdots$ & $\cdots$ \\
\hline 371 & 20.95 & 1.31 & 748.18 & 15.24 & 0.43 \\
\hline 372 & 21.98 & 1.32 & 702.80 & 15.21 & 0.70 \\
\hline 373 & 21.44 & 1.26 & 775.84 & 15.16 & 0.57 \\
\hline 374 & 21.77 & 1.29 & 707.99 & 15.20 & 0.68 \\
\hline
\end{tabular}

\section{Results of the Multi-Objective Genetic Algorithm (MOGA)}

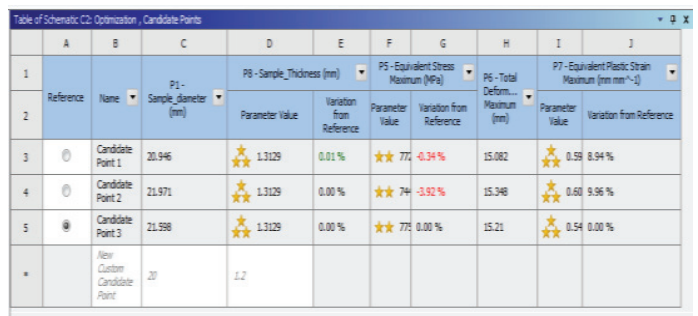

Fig. 5. Table of Schematic C2: Optimization, Candidate Points

For example, applying a CCD in a fractional factorial scheme, a dozen times more sampling points are required for some input parameters, that is, as many evaluations as Finite Element Analysis, which means a significant computational time is consuming, G. Gantar, T. Pepelnjak, K Kuzman [6].

The MOGA method (Multi-Objective Genetic Algorithm), fig. 2, is a variant of the popular Nondominated Sorted Genetic Algorithm-II (NSGA-II) based on controlled elitism concepts. It supports multiple objectives and constraints and aims at finding the global optimum, Ansys manual [7].

The method's Configuration is: will generate 100 samples initially, 50 samples per iteration and find 3 candidates in a maximum of 20 iterations, fig. 3 .

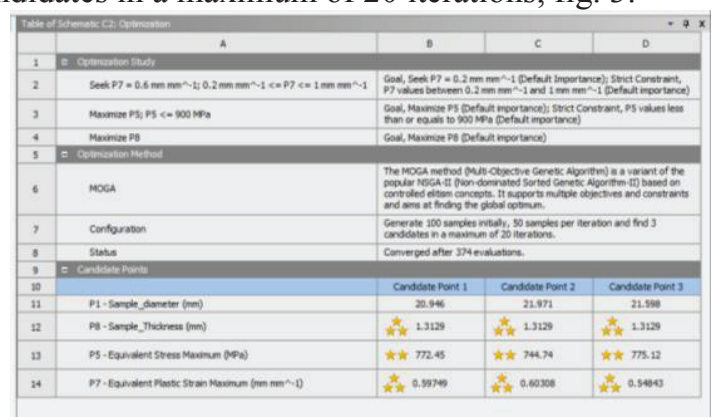

Fig. 3. Table of Schematic C2: Optimization(Optimization Study; Optimization Method; Candidate Points)

Our application was realized after 4 hours of computing time; the results are concentrated on four modules: Candidate Points, Tradeoff, Samples, and Sensitivities. The method converged after 374 Design Points evaluated(Table 1).

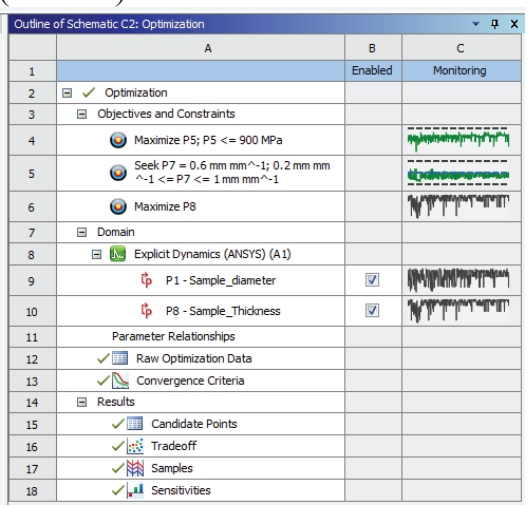

Fig. 4. Outline of Schematic C2: Optimization 


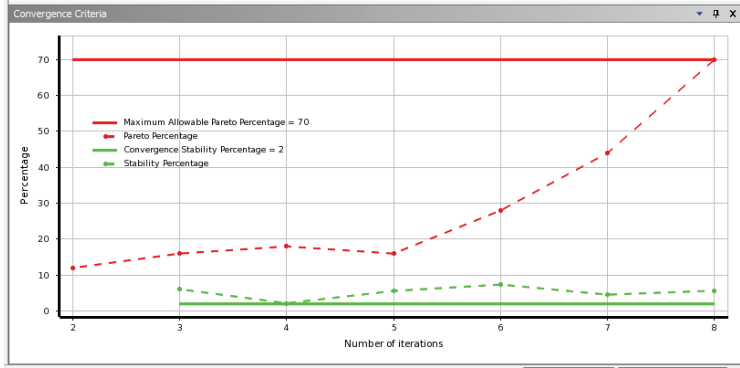

Fig. 6. Convergence Criteria

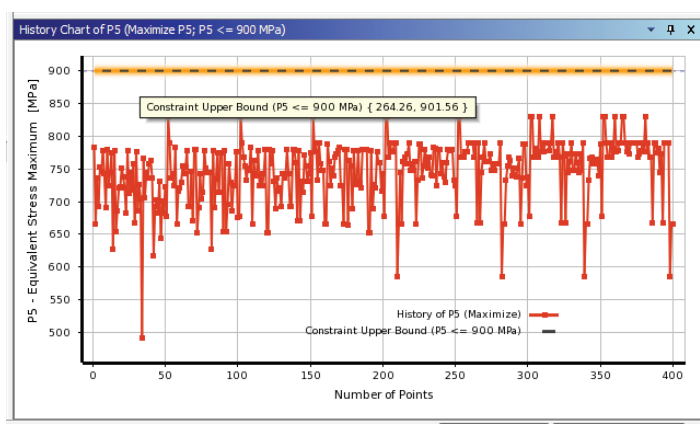

Fig. 7. History Chart of parameter P5 (Maximize P5Equivalent Stress Maximum)

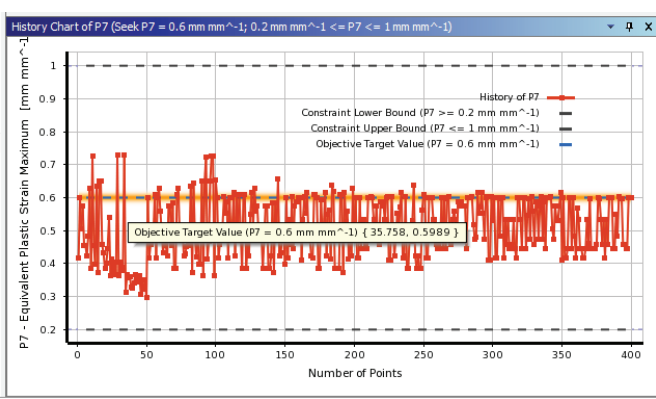

Fig. 8. History Chart of parameter P7 (Seek P7- Equivalent Plastic Strain Maximum)

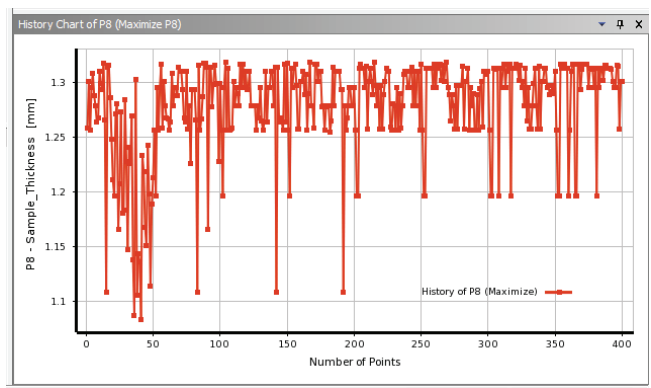

Fig. 9. History Chart of parameter P8

(Maximize P8-Sample Thickness)

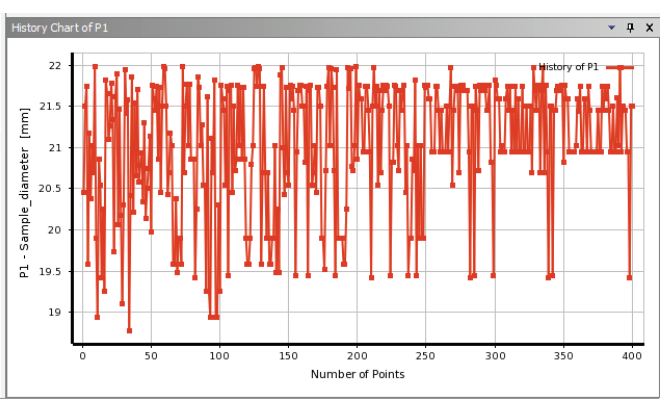

Fig. 10. History Chart of parameter P1 (Sample_diameter)

\footnotetext{
$\overline{{ }^{*} \text { Corresponding author: grebe@uoradea.ro }}$
}

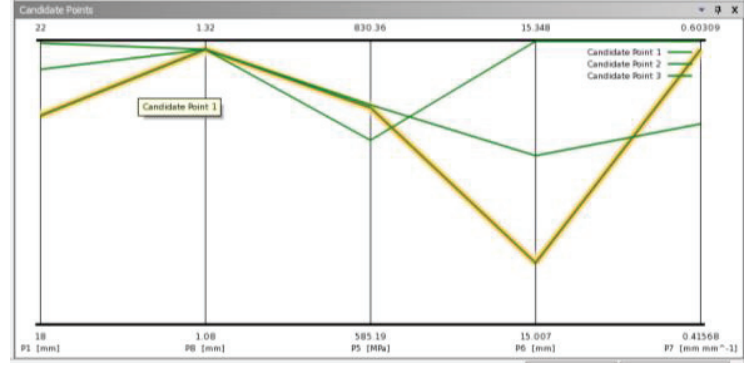

Fig. 11. Candidate Points

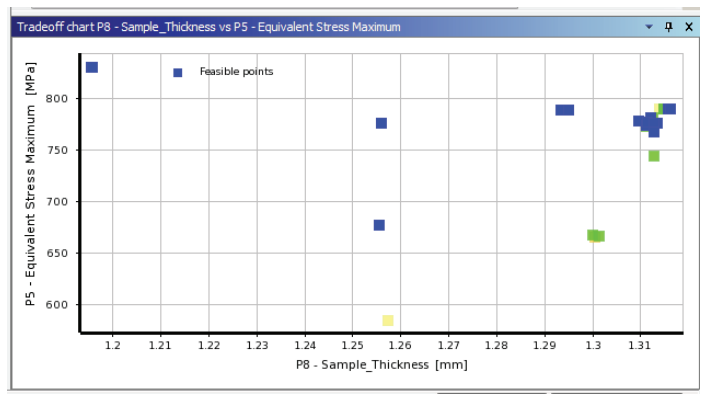

a)-Sample_Thickness vs. Equivalent Stress Maximum

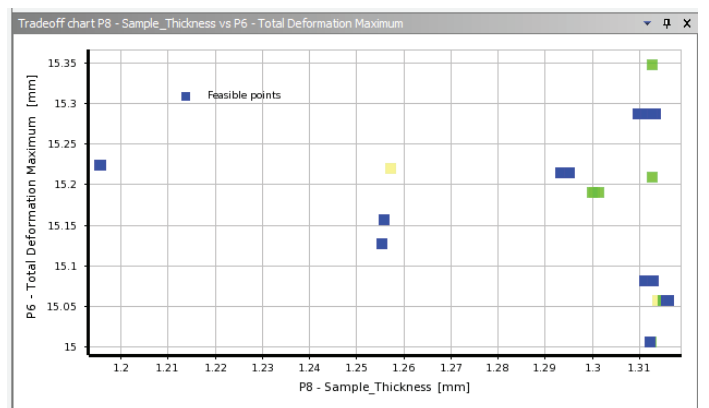

b)-Sample_Thickness vs. Total Deformation Maximum

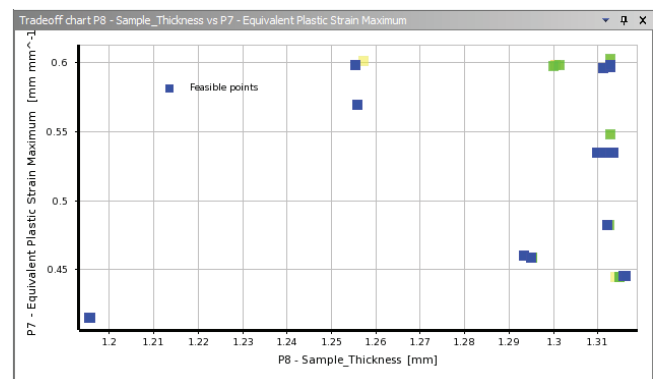

c)-Sample_Thickness vs Equivalent Plastic Strain Max.

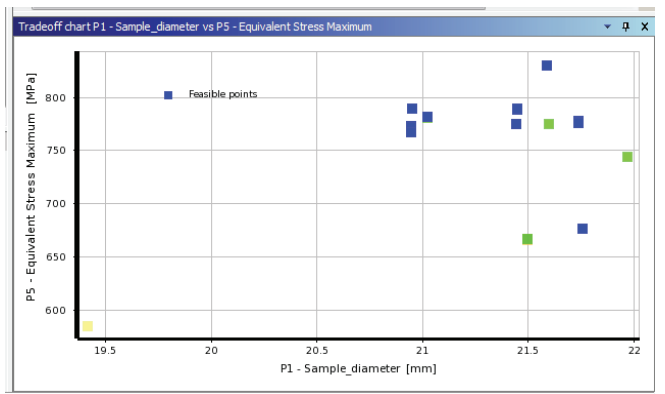

d)- Sample_diameter vs Equivalent Stress Maximum 


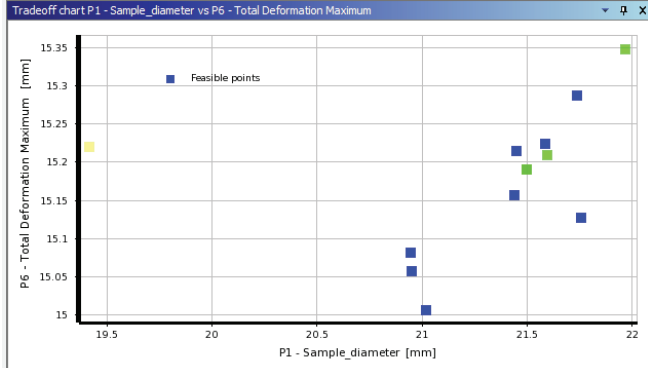

e)-Sample_diameter vs Total Deformation Maximum

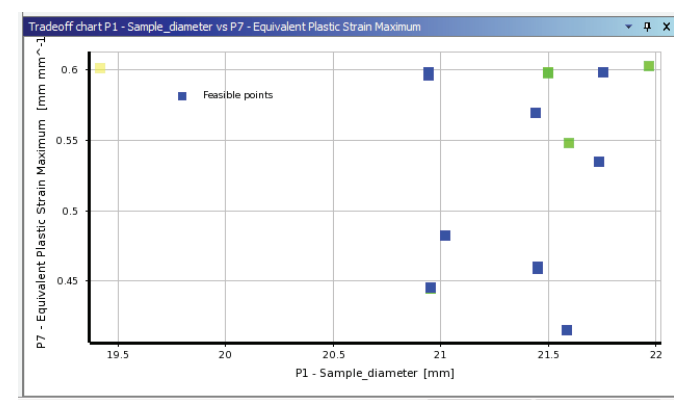

f)- Sample_diameter vs Equivalent Plastic Strain Max.

Fig. 12. Tradeoff-feasible points-2D

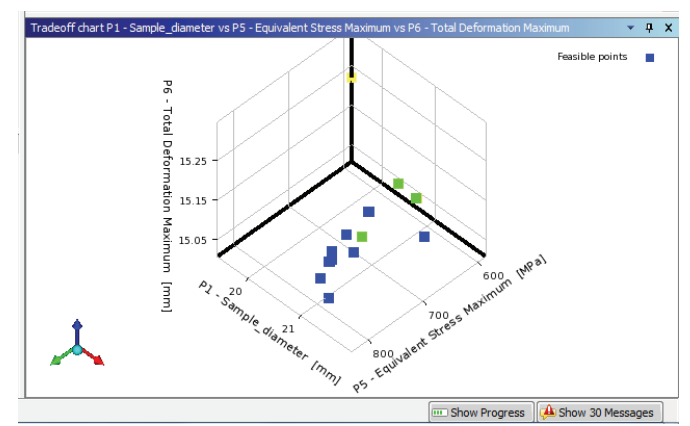

a)-Sample_diameter vs Equivalent Stress Maximum vs Total Deformation Maximum

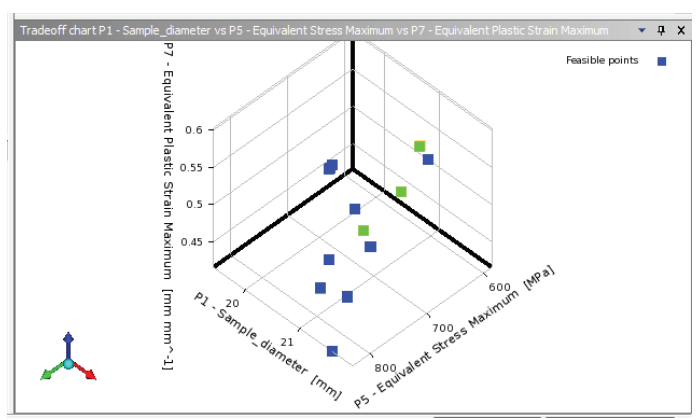

b)-Sample_diameter vs Equivalent Stress Maximum vs Equivalent Plastic Strain Maximum

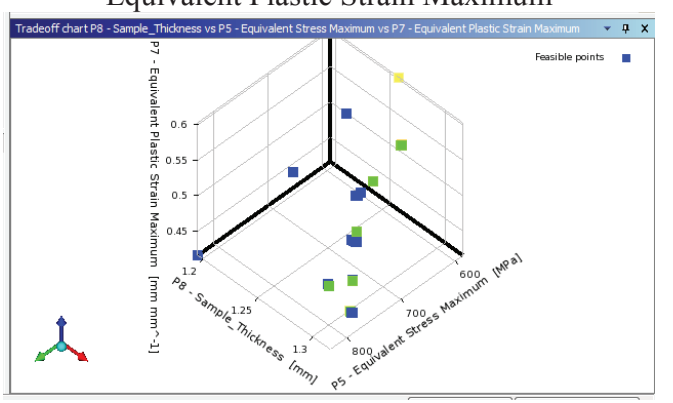

c) -Sample_Thicknrss vs Equivalent Stress Maximum vs Equivalent Plastic Strain Maximum

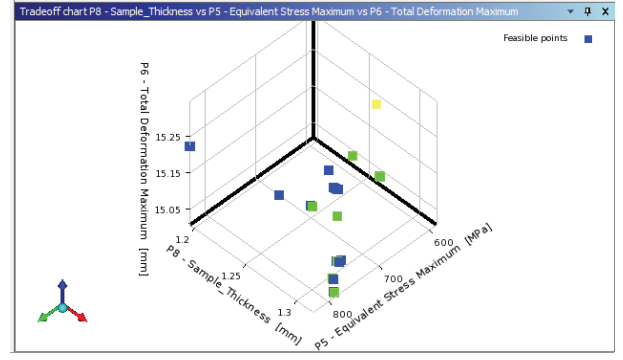

d) - Sample_Thicknrss vs. Equivalent Stress Maximum vs. Total Deformation Maximum

Fig. 13. Tradeoff-feasible points-3D

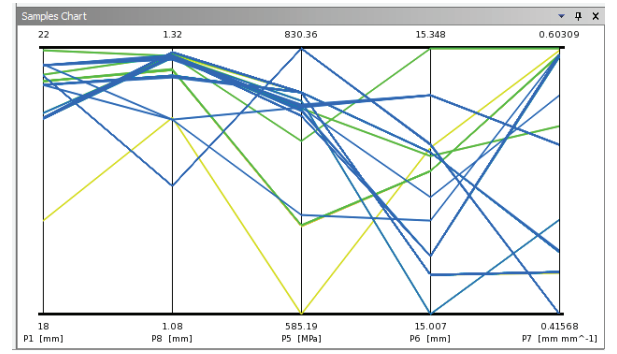

Fig. 14. Samples Chart

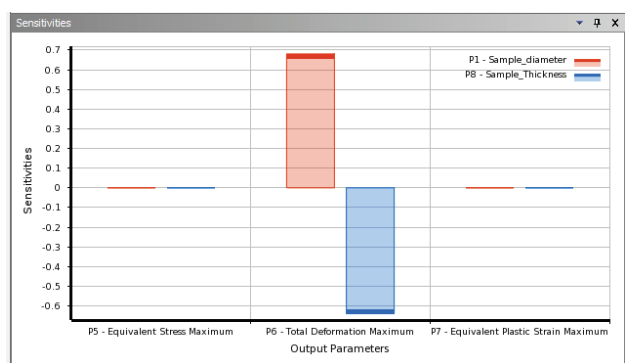

Fig. 15. The Sensitivities of output parameters with respect on input parameters

Response Surface created based on MOGA Optimization are:

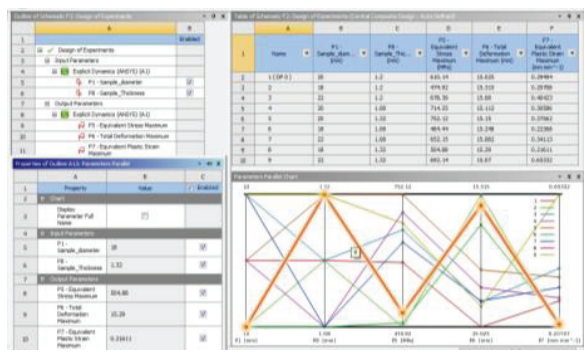

Fig. 16. Design of Experiments(Central Compozite Design) and Parameters Parallel Chart

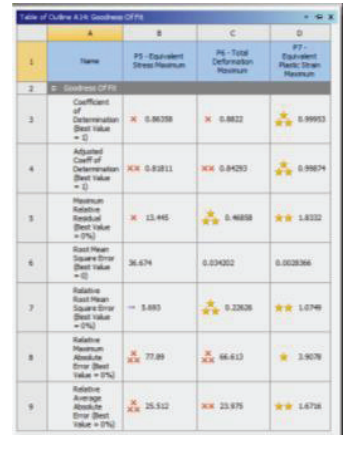

Fig. 17. Table of Outline A14: Goodness Of Fit

\footnotetext{
${ }^{*}$ Corresponding author: grebe@,uoradea.ro
} 


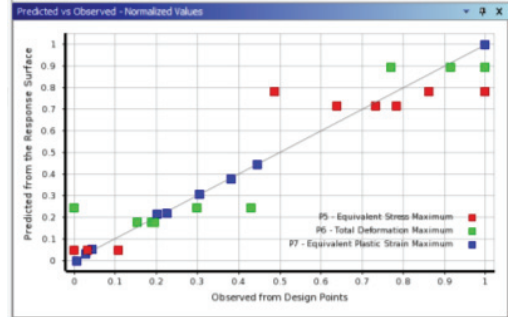

Fig. 18. Goodness of fit for Predicted Point vs. Observed Point

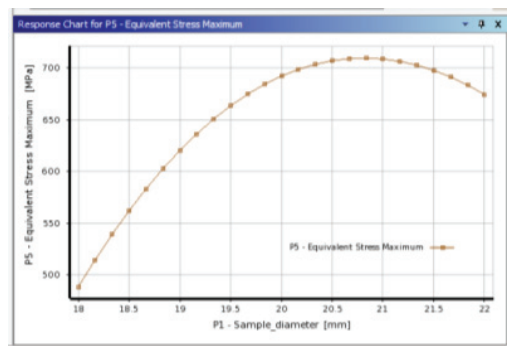

a) Sample_diameter vs Equivalent Stress Maximum

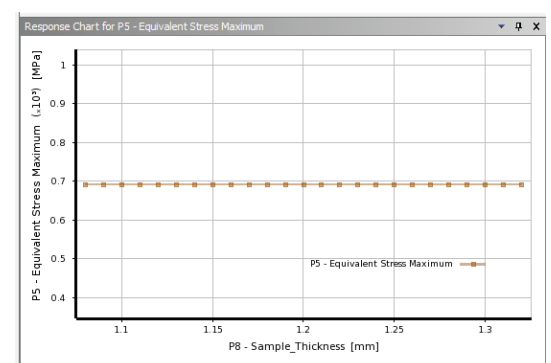

b)- Sample_Thickness vs. Equivalent Stress Maximum

Fig. 19. Response Surface(2D)

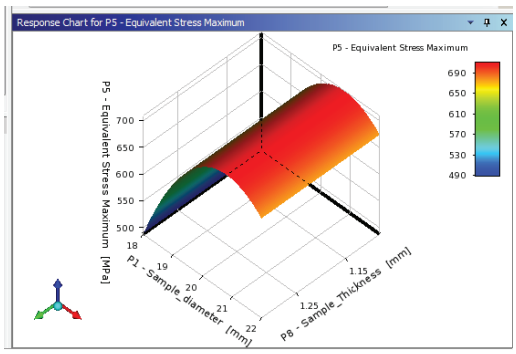

a)-Sample_diametervs. Sample_Thickness vs. Equivalent Stress Maximum

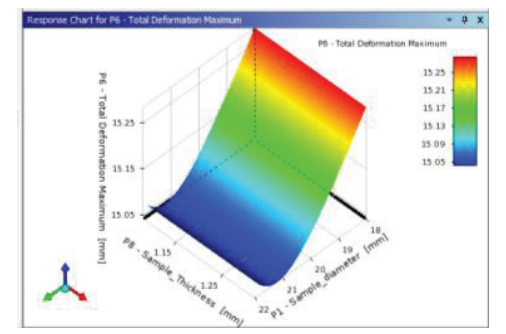

b)-Sample_diameter vs. Sample_Thickness vs. Total Deformation Maximum

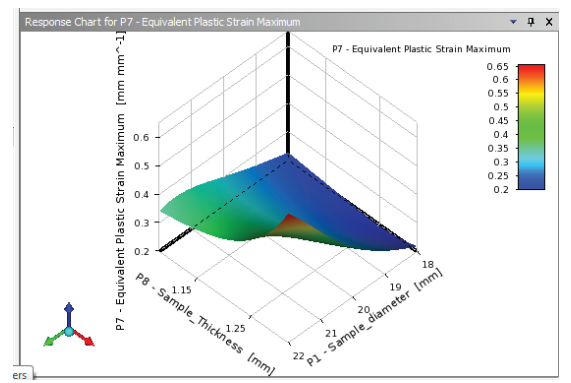

c)-Sample_diameter vs. Sample_Thickness vs. Equivalent Plastic Strain Maximum

Fig. 20. Response Surface(3D)-Equivalent Stress Maximum

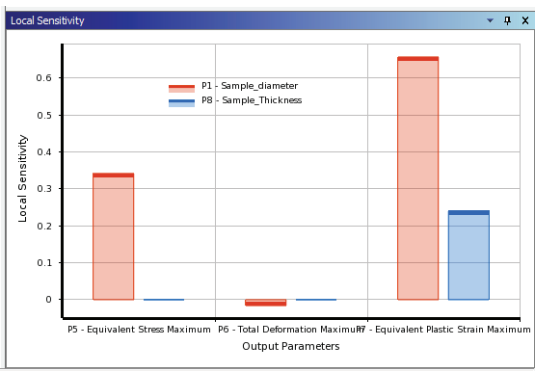

Fig. 21. Local Sensitivity of output parameters with respect on input parameters

\section{References}

[1] M. Diehl, F. Glineur, E. Jarlebring, W. Michiels, Recent Advances in Optimization and itsApplications in Engineering, Springer, 2010.

[2] A. D. Belegundu and T. R. Chandrupatla, Optimization Concepts and Applications in Engineering, Prentice Hall 1999.

[3] G. Grebenişan and S. Mureşan, Numerical Study Of Volumic Forming On Superplastic Behaviour, Annals of The University of Oradea. Fascicle of Management and Technological Engineering, Volume XVI (VI), ISSN 1583-0691, DOI: 10.15660/AUOFMTE.2007.714, 2007.

[4] M.M. Rahman, "Optimization of Process Parameters on Ti-6Al4V Using Central Composite Design Method", Advanced Materials Research, Vols. 189-193, pp. 1393-1400, 2011

[5] J.-P. Ponthot, J.-P. Kleinermann, A cascade optimization methodology for automatic parameter identification and shape/process optimization in metal forming simulation, Elsevier Science B.V., Comput. Methods Appl. Mech. Engrg. 195 (2006) 5472-5508.

[6] G. Gantar, T. Pepelnjak, K Kuzman, Optimization of sheet metal forming processes by the use of numerical simulations, Elsevier Science B.V., Journal of Materials Processing Technology 130131 (2002) 54-59.

[7] Ansys manual, (ANSYS Help Viewer).

\footnotetext{
${ }^{*}$ Corresponding author: grebe@uoradea.ro
} 